\title{
PROFILE OF TYPE 2 DIABETES MELLITUS IN ACUTE THROMBOTIC STROKE
}

\author{
Danny Randy Jordan ${ }^{1}$, Wardah Rahmatul Islamiyah ${ }^{2}$, Jongky Hendro Prayitno ${ }^{3}$ \\ Correspondence: dannyrandyjordan@gmail.com \\ ${ }^{I}$ Medical Doctor Program Faculty of Medicine Airlangga University, Surabaya, Indonesia \\ ${ }^{2}$ Department of Neurology Faculty of Medicine Airlangga University, Surabaya, Indonesia \\ ${ }^{3}$ Department of Internal Medicine Faculty of Medicine Airlangga University, Surabaya, Indonesia
}

\section{Article History:}

Received: October 4, 2018

Accepted: December 17, 2018

Published: July 1, 2019

\section{Cite this as:}

Jordan DR, Islamiyah WR,

Prayitno JH. Profile of type 2

diabetes mellitus in acute

thrombotic stroke in neurology

department at dr. soetomo

general hospital. Malang

Neurology Journal; 2019.5:80-

85. DOI:

http://dx.doi.org/10.21776/ub.mnj

.2019 .005 .2 .6

\section{ABSTRACT}

Background: Stroke is a brain disorder in blood circulation that occur suddenly and last more than 24 hours, which is one leading cause of death in the world. One of the main risk factors of stroke is diabetes mellitus type 2 . One complication is that when thrombosis occurs in the brain causing a stroke.

Objective: This study aimed to determine the profile of type 2 diabetes mellitus in patients with acute thrombotic stroke who were treated in the Neurology Department at the Hospital Dr. Soetomo.

Methods: Sampling was done with purposive sampling by observing the medical records of patients in the period of January 2014 to December 2015 based on inclusion and exclusion criterias that have been set.

Results: Women with a history of type 2 diabetes are more exposed to acute thrombotic stroke; the age group which is most at risk for stroke is between age of 56-60 years; the average duration of DM until the occurence of stroke is $6,54 \pm 4,85$ years; more than two-thirds of patients come to the hospital when the acute thrombotic stroke occurs with a condition of hyperglycemia; the most common comorbid disease is hypertension; and insulin therapy is the most widely used therapy in acute thrombotic stroke patients with type 2 diabetes.

Conclusion: Managing the risk factors of stroke should prolong or prevent the incident of acute thrombotic stroke since most of the patients with type 2 diabetes mellitus came to the hospital with a condition of hyperglycemia and hypertension.

Keywords: Acute thrombotic stroke, type 2 diabetes mellitus, hyperglycemia

\section{Introduction}

Stroke is the circulatory disorders of the brain which is defined as a clinical syndrome of focal or global brain function that occurs suddenly with symptoms that last more than 24 hours or less than 24 hours of patients die, with the primary cause due to disorders of blood circulation of the brain. ${ }^{1}$ It is the fifth largest cause of death in the United States that killed nearly 130,000 people each year. ${ }^{2}$ In Indonesia, stroke is the number one killer according to the Agency for Health Research and Development Ministry of Health of the Republic of Indonesia. Number of stroke patients are likely to continue to increase every year, not only attacks the elderly, but also experienced by those who are young and productive. Currently Indonesia is the country with the largest number of stroke patients in Asia and around $87 \%$ of all strokes are ischemic strokes, which are caused when blood flow to the brain is blocked. ${ }^{2}$

Pathological conditions which accompany an individual such as hypertension, diabetes, heart disease, and high cholesterol (dyslipidemia) are major risk factors (the dominant factor) stroke. Diabetes mellitus as one of the main factors is also a disease that is often suffered by many people and has now become a global health problem as well. Nearly 26 million people in the United States about $8 \%$ of the population have diabetes, while 79 million people have pre-diabetes, a condition in which blood glucose levels are higher than normal. ${ }^{3}$ While in Indonesia, more than 10 million cases of diabetes in $2015 .^{4}$

The increase in blood glucose levels that occur in the first 48 hours in patients with acute stroke phase, both diagnosed with diabetes mellitus or not, affect the mortality and morbidity of patients. ${ }^{5}$ Diabetes mellitus contributes to approximately one-quarter of all stroke cases and increases the stroke risk by twofold to fivefold. More than $90 \%$ of stroke cases are ischemic in nature Diabetes mellitus was also reported as an independent factor of death in patients suffering from stroke. ${ }^{6}$ Stroke patients who suffer from diabetes have a higher mortality rate than those without diabetes. $^{5,6}$

Several studies on the relationship of type 2 diabetes mellitus with the incident thrombotic strokes showed that risk factors for diabetes is the dominant factor in thrombotic strokes, but until now there has been no research data on the profile of type 2 diabetes mellitus that increases the risk of stroke because not all diabetic patients will eventually suffer an acute thrombotic stroke. 
Based on the above explanation, author will conduct research on the profile of type 2 diabetes mellitus in patients with acute thrombotic stroke at the RSUD Dr. Soetomo with the aim of knowing the demographic data, duration of diabetes, random blood glucose levels, fasting blood glucose levels, two hours post-prandial blood glucose levels, A1C, comorbidities, and anti-diabetic drugs theraphy that can be undertaken to prevent the patient diabetes mellitus not to fall in stroke complication.

\section{Methods}

This is a descriptive observational with cross-sectional study design. This study used purposive sampling technique. The population of this study is the medical records of acute thrombotic stroke patients treated in Department of Neurology (R. Seruni, R. Seruni A, and R. Seruni B) RSUD Dr. Soetomo from the period of January 2014 to December 2015. While the sample of this study is the medical records of acute thrombotic stroke patients with history of type 2 diabetes mellitus patients treated in Department of Neurology (R. Seruni, R. Seruni A, and R. Seruni B) RSUD Dr. Soetomo based on inclusion and exclusion criterias that have been set. Inclusion criterias conclude complete data of demography, duration of diabetes, random blood glucose levels, fasting blood glucose levels, two hours post-prandial blood glucose levels, A1C, comorbidities, and anti-diabetic drugs theraphy or at least no more than one of the variables above is absent. Exclusion criterias consist of medical records of acute thrombotic stroke patients with severe infection disease (sepsis) and or metabolic disorders other than diabetes mellitus type 2 and or other types of stroke.

The variables of this study consist of demographic data (gender and age); duration of diabetes which is the time (year) after the patient has been diagnosed with type 2 diabetes mellitus until the occurence of stroke attack; random blood glucose levels, fasting blood glucose levels, two hours post-prandial blood glucose levels, and A1C which are tested recently when first entered the hospital; comorbid diseases other than type 2 diabetes mellitus; and anti-diabetic drugs theraphy.

The data is collected by observing the medical records of patients in the medical records center of RSUD Dr. Soetomo. The scientific ethical committee of RSUD Dr. Soetomo has approved the study and since this study requires no direct contact with patients, the safety monitoring is done by maintaining the confidentiality of patient data.

\section{Results}

\section{Demographic data}

Acute thrombotic stroke patients with type 2 diabetes mellitus based on gender and age (Table 1). The most frequent female patients is in the age range of 56-65 years which is 17 patients $(26,56 \%)$, whereas male patients in this age range are 9 patients $(14,06 \%)$. The female patients is also more in the age range between 46-55 years with 11 patients $(17.19 \%)$ than in male patients. While the male patients are more frequent in the range of age <46 years with 2 patients $(3.13 \%)$ and $>65$ years with the number of 12 patients $(18.75 \%)$ than female patients.
Table 1. Demographic table of patients based on gender and age.

\begin{tabular}{llll}
\hline \multirow{2}{*}{$\begin{array}{c}\text { Age } \\
(\text { year })\end{array}$} & \multicolumn{2}{c}{ Gender } & \multicolumn{2}{c}{$\begin{array}{l}\text { Total } \\
\text { Percentage }\end{array}$} \\
\cline { 2 - 3 }$(\boldsymbol{\%})$
\end{tabular}

\section{Duration of diabetes}

The average duration of type 2 diabetes mellitus in this study is $5.6 \pm 4.85$ years with a median of 5 years. The duration of type 2 diabetes mellitus shortest to the onset of acute thrombotic stroke in this study lies in 0.16 years or two months, whilst the longest is 20 years. In the division by gender, male patients have a shorter average duration, which is $5.34 \pm 4.1$ years than the female patients, which is $5.84 \pm 5.56$ years. The duration of type 2 diabetes based on gender are grouped into three intervals, $\leq 5$ years, 6 - 10 years and $\geq 10$ years. But in this study, there are 25 patients with unknown duration, so author added an unknown group (Figure 1).

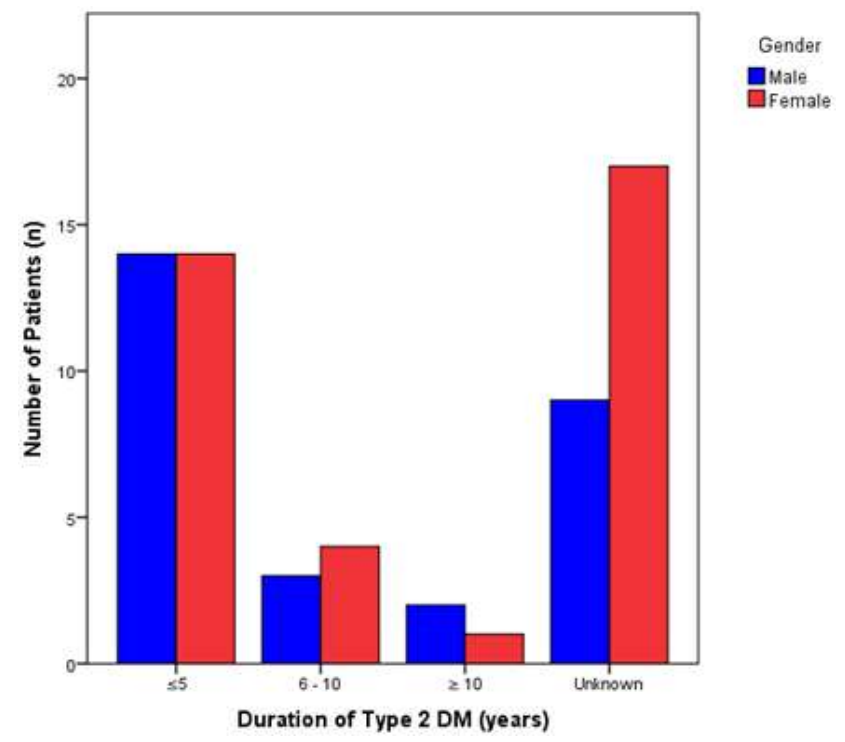

Figure 1. Graph of duration of type 2 diabetes mellitus based on gender.

Blood glucose levels in patients with acute thrombotic strokes

Laboratory data to check the patient's blood glucose levels during an attack of acute thrombotic stroke is divided into four, random blood glucose, fasting blood glucose, two hours post prandial blood glucose, and A1c. (Table 2) Based on the results of the study, most patients come to the hospital with hyperglycemia as evidenced by the percentage level of random blood glucose $(64.06 \%)$, fasting glucose $(81.25 \%)$, two hours post prandial glucose $(68.75 \%)$, and A1C (85.94\%).

Comorbidity in acute thrombotic stroke patients with type 2 diabetes mellitus 
Study results that comorbidity in acute thrombotic stroke patients with type 2 diabetes mellitus are hypertension, decompensatio cordis, acute lung oedema (ALO), old myocardial infarction (OMI), atrial fibrillation, conjunctivitis, asthma, and coronary heart disease (CHD) (Table 3) From some comorbid diagnoses, hypertension is the most frequent comorbid disease with 62 patients $(96.88 \%)$. While other comorbid diseases are low in frequency. In notation that one patient could be diagnosed with more than 1 comorbid disease.

\section{Anti-diabetic drugs use in acute thrombotic stroke patients}

There are three types of anti-diabetic drugs therapy in the treatment of type 2 diabetes mellitus, oral antidiabetic drugs (OADs), insulin, or a combination of the two therapies. The use of insulin as a therapy is the therapy with the highest percentage of $71.88 \%$ (Figure 2 ).

Table 2. Descriptive table of blood glucose levels in acute thrombotic stroke patients.

\begin{tabular}{lccc}
\hline Blood Glucose Levels & $\begin{array}{c}\text { Number of Patients } \\
(\boldsymbol{n}=\mathbf{6 4})\end{array}$ & Male $(\boldsymbol{n}=\mathbf{2 8})$ & Gender \\
\cline { 3 - 4 } & & & \\
\hline Random, mg/dL $(\boldsymbol{n}=\mathbf{3 6})$ \\
Mean \pm SD & $277,08 \pm 141,73$ & $250,75 \pm 97,27$ & $297,56 \pm 166,96$ \\
Median (Min.- Maks.) & $261,5(47-800)$ & $250(47-508)$ & $297,5(81-800)$ \\
Fasting, mg/dL & & & $195,28 \pm 80,04$ \\
Mean \pm SD & $184,98 \pm 69,25$ & $171,75 \pm 50,69$ & $199(60-348)$ \\
Median (Min.- Maks.) & $178,5(60-348)$ & $167,5(68-331)$ & $236,72 \pm 77,83$ \\
2 Hours PP, mg/dL & & & $229(82-374)$ \\
Mean \pm SD & $243,13 \pm 73,43$ & $230,79 \pm 68,61$ & \\
Median (Min.- Maks.) & $225(82-392)$ & $223,5(91-392)$ & $9,0 \pm 2,4$ \\
A1C, \% & $8,9 \pm 2,2$ & & $9,1(5,7-13,4)$ \\
Mean \pm SD & $8,9(5,1-13,4)$ & $8,6(5,1-13,2)$ & \\
Median (Min.- Maks.) & & &
\end{tabular}

Table 3. Comorbidity table of acute thrombotic stroke with type 2 diabetes mellitus.

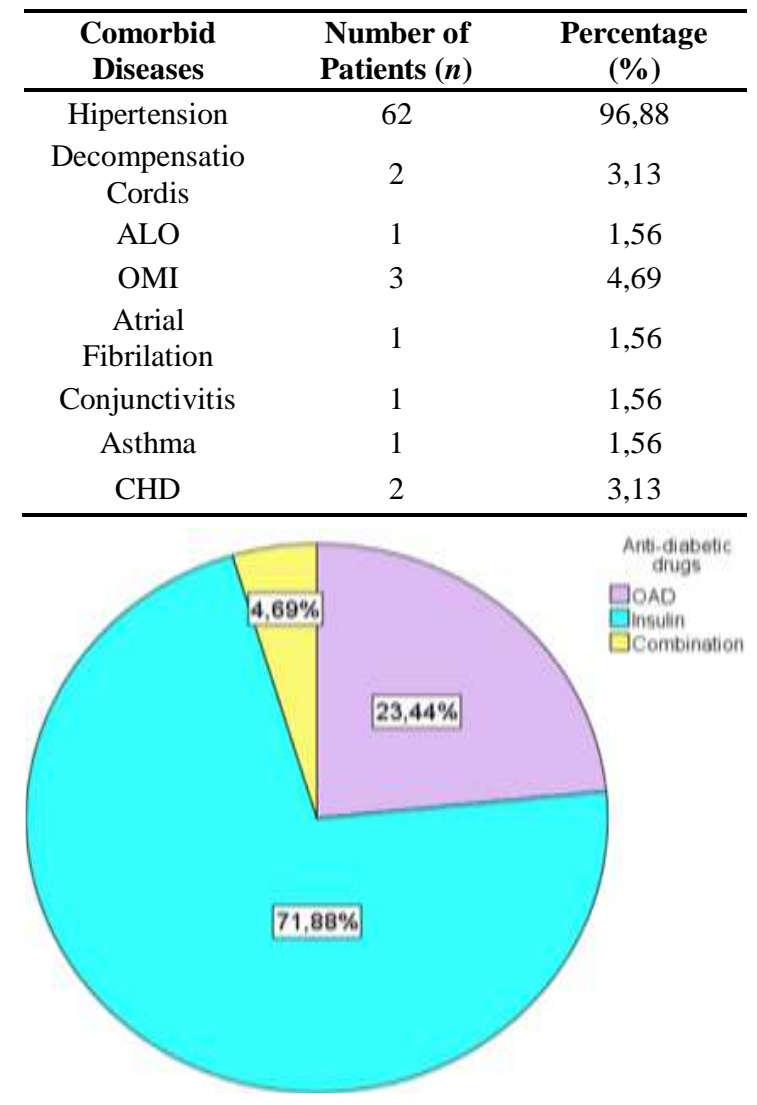

Figure 2. Diagram of anti-diabetic drugs use.

\section{Discussion}

This study shows that the sample of female who were diagnosed with acute thrombotic stroke with history of type 2 diabetes mellitus is more than the male. This result is contradictory with a study from Norway showed that among 283 type 2 diabetes mellitus patients with acute ischemic stroke, $179(63 \%)$ patients were male. ${ }^{7}$ However, the results of a study in the Journal of the National Center for Health Statistics, the sex of the affected individuals ischemic stroke the first time, found an average incidence of ischemic stroke a lot more female than male. ${ }^{8}$ The same result is said by a population-based cohort study in Rancho Bernando states people with diabetes mellitus have a relative risk factor of stroke of 1.8 in men and 2.2 in women. ${ }^{9}$ This may be associated with a specific condition, namely unique risk factors where in the condition called gestational diabetes is a condition that is caused by glucose intolerance during pregnancy was first discovered and where the condition of diabetes mellitus may remain after delivery.

As for the age, this study found that the most frequent range of age was between 56-65 years with 15 patients $(40.62 \%)$. Comparing to the results from Denmark study, conducted in 2004 showed that an increase in ischemic stroke risk factors at age $55-64^{10}$ and according to a Rotterdam Study, the percentage of the age group > 55 years more likely to suffer a stroke compared with the age group of 40-55 years. ${ }^{11}$ After the age of 50 years, an appearing tendency that the small cerebral arteries were also affected the process of 
atherosclerosis. Constriction caused by atherosclerotic plaque can include 80 to $90 \%$ of the arterial lumen. ${ }^{12}$

Relating between gender and age, the study results showed that the female subjects with age $\leq 65$ years are more than men. But after age $\geq 66$ years, the male subjects are more than the female. The relative risk of stroke incidence with a history of type 2 diabetes is significantly increased in men with age $<55$ years and $>64$ years. Whereas in women, the relative risk increased substantially in the age range 55-64 years. ${ }^{10}$ This is slightly different from the results of this study. This may be associated with other risk factors that cause rapid attack of acute thrombotic stroke occurs first, such as hypertension, high lipid levels, body mass index (BMI), and others.

A decrease in frequency along with the long duration of type 2 diabetes among men and women signal the occurrence of stroke is more common in the time interval $\leq$ 5 years based on this research. But the Northern Manhattan study reported that the long suffering from diabetes associated with the incidence of ischemic stroke, compared with non-diabetic patients, long suffering from DM 1.7 times the risk of 0-5 years, 5-10 years of 1.8 times, and $\geq 10$ years of risk 3.2 times. ${ }^{13}$ The longer duration of diabetes, the higher the risk of acute stroke. This is presumably because the existence of other factors that accelerate the incidence of stroke in patients with type 2 diabetes, for example, blood glucose levels are steeper in the long term uncontrolled and unhealthy lifestyles, such as smoking. Mentioning that there are 25 patients with unknown duration and based on the results of the study, the levels of $\mathrm{HbA1c}$ in unknown group average of $\geq 6.5 \%$. Gaps in the data of this study was supported by a research from Australia which classified patients with hyperglycemia in the acute phase of stroke into 4 groups: patients who knew that they were with diabetes mellitus; new patients known to suffer from diabetes mellitus at the time; patients with impaired fasting glucose; and unknown underlying disease, also referred to as stress hyperglycemia (reactive hyperglycemia). Between $5-28 \%$ of stroke patients have undiagnosed diabetes before. ${ }^{14}$

The majority of acute thrombotic stroke patients with a history of type 2 diabetes mellitus come to the hospital with a condition of high blood glucose levels (hyperglycemia). A study from America Heart Association shows the condition of hyperglycemia seen in patients upon hospital admission approximately $2 / 3$ of patients who are diabetic, and approximately $40 \%$ in non-diabetic patients, with an overall incidence of hyperglycemia approximately $50 \%$ in patients with stroke. ${ }^{15}$ Meanwhile, according to a research from Denmark, hyperglycemia occurs in $60 \%$ of cases of acute stroke and $12-53 \%$ in the case of acute stroke without any previous history of diabetes. ${ }^{16}$ By contrast, a study from Indonesia showed a result that only $28,9 \%$ patients with acute ischemic stroke came to the hospital with hyperglycemic condition. But it also concludes that normal random blood glucose level shows better improvement and better outcome. $^{17}$

There have been no studies that indicate with certainty that hyperglycemia can cause acute thrombotic stroke directly, but there is a theory that explains that hyperglycemia worsens the prognosis of acute stroke. Hyperglycemia may have direct impact on ischemic brain. Although the mechanism is not fully understood, and intracellular accumulation of lactic acidosis in ischemic brain (brain glucose metabolism is produced through anaerobic) can contribute in this regard. Intracellular acidosis supports and accelerates ischemic injury by increasing lipid peroxidation and free radical formation, which allows the accumulation of intracellular calcium, and impair mitochondrial function. Neurotoxic effects of these play an important role in the ischemic penumbra (a region in the brain tissue surrounding the core of the infarcted tissue in which neurons were wounded but still survived). ${ }^{18}$ A reduction of $24 \%$ in local blood flow caused by hyperglycemia, reduces blood circulation to the ischemic area and causes an ischemic penumbra becomes infarction. ${ }^{19}$

The results of this study showed hypertension is the most frequent comorbid illness $(96.88 \%)$. Note that in this study, dyslipidemia is not included in the inclusion criteria for ruling out the lipid factor in the incidence of acute thrombotic stroke. Study in Northern Kentucky showed that risk factors for ischemic stroke in patients with type 2 diabetes, which are a history of hypertension, history of myocardial infarction, high cholesterol levels, and age $<55$ years. $^{20}$ This indicates with hypertension alone is a strong risk factor to the incidence of stroke with pathophysiological mechanisms of its own. A theory of pathophysiology of diabetes with comorbid hypertension that caused the stroke explains atherosclerotic changes in extracranial and intracranial vessels are caused due to insulin resistance by the cells and hyperinsulinemia which cause diabetes and not due to high glucose levels or other risk factors. $^{21}$

Regular insulin was used in blood glucose control during the acute phase of stroke given subcutaneously every 6 hours by means of a sliding scale or continuous intravenous infusion. Management of hyperglycemia in the acute phase of stroke, according to The European Stroke Organization guideline, is when the blood glucose levels $\leq 180 \mathrm{mg} / \mathrm{dL}$ insulin were not given, insulin delivery started to be given at blood glucose levels > $180 \mathrm{mg} / \mathrm{dL} .{ }^{22}$ Diabetic patients controlled with diet and oral hypoglycemic drugs, in the acute phase of stroke require insulin therapy. Similarly, in patients with diabetes mellitus who usually get insulin therapy will require increasing doses of insulin during the acute phase of stroke. The goal for blood glucose level is in a range of $140 \mathrm{mg} / \mathrm{dL}$ to $180 \mathrm{mg} / \mathrm{dL}^{22,23}$ However, according to World Journal of Diabetes, intensive glycaemic therapy only reduced long-term risk of hypertension by $24 \%$ (HR=0.76; 95\%CI: 0.64-0.92). This suggests that standard cardiovascular risk factors gain more importance as glycaemic control improves. ${ }^{24}$

There are several weaknesses in this study, which are using secondary datas and there medical records of patients which did not have complete data, so it can not be analyzed. This study also does not use comparative datas (data of diabetic patients without incidence of stroke or data of stroke patients without a history of diabetes) so that the results of the research can not be concluded with certainty.

\section{Conclusion}

Managing the risk factors of stroke should prolong or prevent the incident of acute thrombotic stroke since most of the patients with type 2 diabetes mellitus came to the 
hospital with a condition of hyperglycemia and hypertension.

Author expects writing more complete medical records to facilitate the study and further study on the correlation of risk factors for diabetes mellitus type 2 with the incidence of acute thrombotic stroke.

\section{Acknowledgement}

The authors would like to thank to Airlangga University and Dr. Soetomo General Hospital, Surabaya, East Java, Indonesia for facilitating this research.

\section{References}

1. Sacco RL, Kasner SE, Broderick JP, Caplan LR, Connors JJ, Culebras A, et al. An Updated definition of stroke for the 21st century. Stroke; 2013.44(7):2064-89. DOI: http://dx.doi.org/10.1161/STR.0b013e318296aeca

2. Murphy SL, Kochanek KD, Xu J, Arias E. Mortality in the united states. NCHS Data Brief; 2015.(229):1-8. DOI:

http://dx.doi.org/10.1056/NEJM184002260220306

3. World Health Organization. Global report on diabetes. WHO; 2016.978:88. Available from: http://www.who.int/about/licensing/\%5Cnhttp://apps. who.int/iris/bitstream/10665/204871/1/978924156525 7_eng.pdf

4. International Diabetes Federation. Annual report 2015; 2015.1-29. Available from: http://www.idf.org/sites/default/files/IDF_AnnualRepo rt_2015_WEB.pdf

5. Gentile NT, Seftchick MW, Huynh T, Kruus LK, Gaughan J. Decreased mortality by normalizing blood glucose after acute ischemic stroke. Academic Emergency Medicine; 2006.13(2):174-80. DOI: http://dx.doi.org/10.1197/j.aem.2005.08.009

6. Al-Rubeaan, Khalid, et al. Ischemic Stroke and Its Risk Factors in a Registry-Based Large CrossSectional Diabetic Cohort in a Country Facing a Diabetes Epidemic. Journal of Diabetes Research, vol. 2016, 2016, pp. 1-9. DOI: http://dx.doi.org/10.1155/2016/4132589.

7. Nacu A, Thomassen L, Fromm A, Bjerkreim A, Andreassen U, Naess H. Impact of diabetes mellitus on 1867 acute ischemic stroke patients. a bergen norstroke study. Journal of Research in Diabetes; 2015.Sep;:111. DOI: http://dx.doi.org/10.5171/2015.112104

8. Arboix A, Milian M, Oliveres M, García-Eroles L, Massons J. Impact of female gender on prognosis in type 2 diabetic patients with ischemic stroke. European Neurology; 2006.56(1):6-12.

DOI: http://dx.doi.org/10.1159/000094249

9. Kanaya AM, Barrett-Connor E, Gildengorin G, Yaffe $\mathrm{K}$. Change in cognitive function by glucose tolerance status in older adults. Archives of Internal Medicine; 2004.164(12):1327.

DOI: http://dx.doi.org/10.1001/archinte.164.12.1327

10. Almdal T, Scharling H, Jensen JS, Vestergaard H. The independent effect of type 2 diabetes mellitus on ischemic heart disease, stroke, and death. Archives of Internal Medicine; 2004.Dec;164(13):1422. DOI: http://dx.doi.org/10.1001/archinte.164.13.1422
11. Hollander M. Incidence, risk, and case fatality of first ever stroke in the elderly population. The Rotterdam Study. Journal of Neurology, Neurosurgery \& Psychiatry; 2003.Jan;74(3):317-21. DOI: http://dx.doi.org/10.1136/jnnp.74.3.317

12. Feigin VL, Forouzanfar MH, Krishnamurthi R, Mensah GA, Connor M, Bennett DA, et al. Global and regional burden of stroke during 1990-2010: findings from the Global Burden of Disease Study 2010. Lancet; 2014.383(9913):245-54. DOI: http://dx.doi.org/10.1016/S0140-6736(13)61953-4

13. Banerjee C, Moon YP, Paik MC, Rundek T, MoraMclaughlin C, Vieira JR, et al. Duration of diabetes and risk of ischemic stroke. Stroke; 2012.43(5):12127.

DOI: http://dx.doi.org/10.1161/STROKEAHA.111.641381

14. Kiers L, Davis SM, Larkins R, Hopper J, Tress B, Rossiter SC, et al. Stroke topography and outcome in relation to hyperglycaemia and diabetes. Journal of Neurology, Neurosurgery \& Psychiatry; 1992.;55(4):263-70. DOI: http://dx.doi.org/10.1136/jnnp.55.4.263

15. Capes SE, Hunt D, Malmberg K, Pathak P, Gerstein HC. Stress hyperglycemia and prognosis of stroke in nondiabetic and diabetic patients. Stroke; 2001.32(10):2426-32.

DOI: http://dx.doi.org/10.1161/hs1001.096194

16. Perner A, Nielsen SE, Rask-Madsen J. High glucose impairs superoxide production from isolated blood neutrophils. Intensive Care Medicine. 2003;29(4):6425. DOI: http://dx.doi.org/10.1007/s00134-002-1628-4

17. Munir B, Rasyid HA, Rosita R. Relationship between the random blood glucose levels during admission at emergency room with clinical output in acute ischemic stroke patients. Malang Neurology Journal; 2015.1:518.

DOI: http://dx.doi.org/10.21776/ub.mnj.2015.001.02.2

18. Macpherson, Sarah L, et al. "Stroke and Diabetes: a Dangerous Liaison." British Journal of Diabetes, vol. 16, no. 3, 2016, p. 114. DOI: http://dx.doi.org/10.15277/bjd.2016.089.

19. Dandona P, James IM, Newbury PA, Woollard ML, Beckett AG. Cerebral blood flow in diabetes mellitus: evidence of abnormal cerebrovascular reactivity. British Medical Journal; 1978.2(6133):325-6. DOI: http://dx.doi.org/10.1136/bmj.2.6133.325

20. Kissela BM, Khoury J, Kleindorfer D, Woo D, Schneider A, Alwell K, et al. Epidemiology of ischemic stroke in patients with diabetes: the greater cincinnati/northern kentucky stroke study. Diabetes Care; 2005;28(2):355-9. DOI: http://dx.doi.org/10.2337/diacare.28.2.355

21. Alloubani, Aladeen, et al. Hypertension and Diabetes Mellitus as a Predictive Risk Factors for Stroke. Diabetes \& Metabolic Syndrome: Clinical Research \& Reviews, vol. 12, no. 4, 2018, pp. 577-584. DOI: http://dx.doi.org/10.1016/j.dsx.2018.03.009.

22. Fuentes B, Ntaios G, Putaala J, Thomas B, Turc G, Díez-Tejedor E. European Stroke Organisation (ESO) guidelines on glycaemia management in acute stroke. European Stroke Journal; 2017.3(1):5-21. DOI: http://dx.doi.org/10.1177/2396987317742065

23. Powers WJ, Rabinstein AA, Ackerson T, Adeoye OM, Bambakidis NC, Becker K, et al. 2018 Guidelines for 
the early management of patients with acute ischemic stroke: a guideline for healthcare professionals from the american heart association/american stroke association. Stroke; 2018.49(3). DOI: http://dx.doi.org/ 10.1161/STR.0000000000000158
24. Tun NN, Arunagirinathan G, Munshi SK, Pappachan JM. Diabetes mellitus and stroke: A clinical update. World Journal of Diabetes; 2017.8(6):235. DOI: http://dx.doi.org/10.4239/wjd.v8.i6.235 